\title{
Validation of a new risk score system for non-variceal upper gastrointestinal bleeding
}

Min Seong Kim, Hee Seok Moon ${ }^{1 *}$ (D), In Sun Kwon², Jae Ho Park', Ju Seok Kim¹, Sun Hyung Kang ${ }^{1}$, Jae Kyu Sung ${ }^{1}$, Eaum Seok Lee', Seok Hyun Kim, Byung Seok Lee ${ }^{1}$ and Hyun Yong Jeong ${ }^{1}$

\begin{abstract}
Background: Recently, a new international bleeding score was developed to predict 30-day hospital mortality in patients with upper gastrointestinal bleeding (UGIB). However, the efficacy of this newly developed scoring system has not been extensively investigated. We aimed to validate a new scoring system for predicting 30-day mortality in patients with non-variceal UGIB and determine whether a higher score is associated with re-bleeding, length of hospital stay, and endoscopic failure.
\end{abstract}

Methods: A retrospective study was performed on 905 patients with acute non-variceal UGIB who were examined in our hospital between January 2013 and December 2017. Baseline characteristics, endoscopic findings, rebleeding, admission, and mortality were reviewed. The 30-day mortality rate of the new international bleeding risk score was calculated using the receiver operating characteristic curves and compared to the pre-endoscopy Rockall score, AIMS65, Glasgow Blatchford score, and Progetto Nazionale Emorragia Digestiva score. To verify the variable for the 30-day mortality of the new scoring system, we performed multivariate logistic regression using our data and further analyzed the score items.

Results: The new international bleeding scoring system showed higher receiver operating characteristic (ROC) curve values in predicting mortality (area under ROC curve 0.958; [95\% confidence interval (CI)]), compared with such as AIMS65 (AUROC, 0.832; 95\%Cl, 0.806-0.856; $P<0.001$ ), PNED (AUROC, 0.865; 95\%Cl, 0.841-0.886; $P<0.001$ ), Pre-RS (AUROC, 0.802; 95\%Cl, 0.774-0.827; $P<0.001$ ), and GBS (AUROC, $0.765 ; 95 \% \mathrm{Cl}, 0.736-0.793 ; P<0.001$ ). Multivariate analysis was performed using our data and showed that the 30-day mortality rate was related to multiple comorbidities, blood urea nitrogen, creatinine, albumin, syncope at first visit, and endoscopic failure within $24 \mathrm{~h}$ during the first admission. In addition, in the high-score group, relatively long hospital stay, re-bleeding, and endoscopic failure were observed.

(Continued on next page)

\footnotetext{
*Correspondence: mhs1357@cnuh.co.kr

'Division of Gastroenterology, Departmentof Internal Medicine, Chungnam

National University Hospital, Chungnam National University School of Medicine, 282 Munhwa-ro, Jung-gu, Daejeon 35015, Republic of Korea Full list of author information is available at the end of the article
}

(c) The Author(s). 2020 Open Access This article is licensed under a Creative Commons Attribution 4.0 International License, which permits use, sharing, adaptation, distribution and reproduction in any medium or format, as long as you give appropriate credit to the original author(s) and the source, provide a link to the Creative Commons licence, and indicate if changes were made. The images or other third party material in this article are included in the article's Creative Commons licence, unless indicated otherwise in a credit line to the material. If material is not included in the article's Creative Commons licence and your intended use is not permitted by statutory regulation or exceeds the permitted use, you will need to obtain permission directly from the copyright holder. To view a copy of this licence, visit http://creativecommons.org/licenses/by/4.0/. The Creative Commons Public Domain Dedication waiver (http://creativecommons.org/publicdomain/zero/1.0/) applies to the data made available in this article, unless otherwise stated in a credit line to the data. 
(Continued from previous page)

Conclusion: This is a preliminary report of a new bleeding score which may predict 30-day mortality better than the other scoring systems. High-risk patients could be screened using this new scoring system to predict 30-day mortality. The use of this scoring system seemed to improve the outcomes of non-variceal UGIB patients in this study, through proper management and intervention.

Keywords: Gastrointestinal bleeding, Mortality, Risk assessment

\section{Background}

Acute upper gastrointestinal bleeding (AUGIB) is a common medical emergency, with an incidence of 84-160 cases per 100,000 individuals and a mortality rate of approximately $10 \%$ [1]. More than $70 \%$ of AUGIB cases are non-variceal UGIB (NVUGIB), and peptic ulcer bleeding is the main cause of NVUGIB. Despite the development of endoscopic therapies and pharmacological management, NVUGIB is still associated with considerable rates of mortality and morbidity, and high medical expenses [2-5].

The International Consensus Recommendations on the management of patients with NVUGIB recommend "early risk stratification" using validated prognostic scales [6]. A number of scoring systems have been devised to predict the outcome of patients with AUGIB, including the Rockall (RS) [7], pre-endoscopic Rockall (pre-RS) [8], Glasgow-Blatchford (GBS) [ 9], AIMS65 $[10,11]$, and ProgettoNazionaleEmorragiaDigestiva (PNED) [12] scores. There have been many studies on the outcomes of UGIB and continued study on which scoring systems can better predict mortality. However, limited research has been performed on a unified opinion or a new superior scoring system. Recently, based on an international multicenter study, a newly developed international bleeding score (INBS) was used to predict the 30-day hospital mortality in patients with AUGIB. In the previous study, INBS well predicted the 30-day mortality in UGIB patients compared to the other scoring systems [13]. In this study, we aimed to evaluate whether INBS is effective in predicting 30-day mortality in NVUGIB patients and to determine whether re-bleeding and endoscopic treatment failure were high in the patients with a relatively high INBS score.

\section{Methods}

\section{Patients and data collection}

We retrospectively included patients who visited the emergency room (ER) for AUGIB at the Chungnam National University Hospital in Daejeon, Korea from January 2013 to December 2017. Patients older than 18 years old who presented with NVUGIB symptoms (melena, hematemesis, coffee-ground vomiting, and/or hematochezia) were included in the study. The exclusion criteria for this study were as follows: patients with lower GI, obscure GI, and variceal bleeding; those with post procedural complications; and those who were lost to follow-up after 30 days from visiting the ER.

Data were collected for each patient by reviewing their medical chart. The data included demographic data, comorbidities, chief complaints at first visit, Glasgow Coma score at the time of the emergency room visit, diagnosis including cause of bleeding, presence of endoscopic treatment, outcomes of endoscopic treatment, 30-day in-hospital mortality, length of hospital stay, hemodynamics, and laboratory result. On the basis of these data, the pre-endoscopic Rockall, Glasgow Blatchford, AIMS65, and INBS were calculated on the time of admission. The INBS is measured based on age, comorbidity, and blood test and is weighted according to severity of each category (Table 1). Three endoscopists (HY Jeong, JK Sung, and HS Moon) with more than 15 years of experience in reviewing endoscopic findings using the picture archiving communication system (PACS) classified the findings as gastric ulcers (GUs), duodenal ulcers (DUs), Dieulafoy's lesions, Mallory-Weiss syndrome, esophageal ulcers, angio-

Table 1 International bleeding risk score for predicting 30-day mortality

\begin{tabular}{ll}
\hline Variable & Assigned score \\
\hline Age & 1 \\
$60-74$ years & 2 \\
$\geq 75$ years & \\
Comorbidity & 2 \\
Altered mental status & 2 \\
Liver cirrhosis & 4 \\
Disseminated malignancy & \\
ASA score & 1 \\
3 & 3 \\
$\geq 4$ & \\
Blood tests & 1 \\
Urea $>10 \mathrm{mmol} / \mathrm{L}$ & 2 \\
Albumin $<30 \mathrm{~g} / \mathrm{L}$ & \\
Creatinine & \\
$100-150 \mu \mathrm{mol} / \mathrm{L}$ & 2 \\
$>150 \mu \mathrm{mol} / \mathrm{L}$ &
\end{tabular}


dysplasia, hemorrhagic gastritis, acute gastric mucosal lesion, and cancer-related bleeding. The data for each scoring system were entered by one researcher (MS Kim). Some verified scoring systems, for example, preendoscopy Rockall score, AIMS65, Glasgow Blatchford score, are automatically calculated in the electronical program in our hospital where this study was conducted. However, the new risk score system is not currently fully validated; thus, it was calculated manually. Moreover, to minimize errors and bias, the first author of this paper (MS Kim) managed it.

\section{Definitions}

The grading of overall health comorbidity was performed according to the American Society of Anesthesiologists (ASA) classification [14]. As in previous studies [13], we categorized the patients into the high-risk group or the low-to-moderate-risk group using a cut-off INBS score; the high-risk group included patients with an INBS score $>7$, whereas the low-to-moderate-risk group included patients with an INBS score $\leq 7$.

The primary outcome was in-hospital mortality at 30 days, defined as any death occurring during hospitalization. Secondary outcomes were assessed for recurrence of bleeding (re-bleeding), duration of hospital stay, and endoscopic hemostasis failure at the first visit in the high-risk group.

Re-bleeding was characterized as fresh hematemesis and/or melena associated with the development of shock (pulse $>100$ beats $/ \mathrm{min}$, systolic blood pressure $<100$ $\mathrm{mmHg}$ ), or a reduction in the hemoglobin concentration $>2 \mathrm{~g} / \mathrm{dL}$ for $>24 \mathrm{~h}$. This also included cases of rebleeding upon repeat endoscopy [15].

The hospitalization period was defined as the date from visiting the ER to the date of discharge. Endoscopic hemostasis failure at first visit was defined as instability at the time of first visit and inability to perform endoscopic hemostasis or vascular embolization after angiography or surgery due to endoscopic hemostasis failure.

\section{Statistical analyses}

We compared each scores' discriminative ability to predict 30-day mortality by calculating the area under the receiver operating characteristic curves (AUROCs) with 95\% confidence intervals (CIs). The optimal cut-off score for predicting very high-risk patients in each scoring system was determined by the maximum Youden index, with a sensitivity and specificity of $95 \%$. In addition, the performance of the scoring systems was assessed by calculating the sensitivity, specificity, percentage of patients classified as high risk, and the mortality rate among them.

Based on the risk factors previously mentioned in the scoring systems, univariate and multivariate logistic regression analyses were performed to evaluate the risk factors for predicting the 30-day mortality of NVUGIB patients visiting our hospital. A $P<0.05$ was regarded as statistically significant. This was to ensure that the risk factors mentioned in the other scoring systems were actually a significant risk factor in our database. All statistical analyses were performed with the SPSS (version21.0, SPSS Inc., Chicago, IL, USA) and MedCalc (version18.11,MedCalc ${ }^{\circ}$, MedCalc Software, Belgium).

\section{Results}

Data of 1118 patients aged $\geq 18$ years who visited the ER owing to UGIB for $>5$ years were reviewed. We excluded 213 patients from the study for the following reasons: 23 patients had non-UGIB, 155 had variceal bleeding, 15 had postprocedure-associated bleeding, and 20 had obscure GI bleeding. In total, 905 patients were selected for evaluation. Of these, 131 and 774 patients were included in the high- and low-to-moderate-risk groups, respectively (Fig. 1).

\section{Patients' characteristics}

Of the 905 included patients, 674 (74.5\%) were men and $231(25.5 \%)$ were women, with a mean age of $65.4 \pm$ 14.7 years. Upper GIT endoscopy was performed in all included patients. Seven hundred ten patients (78.4\%) underwent endoscopy within $12 \mathrm{~h}$ during the admission in the emergency room, 160 patients $(17.7 \%)$ underwent endoscopy within $12-24 \mathrm{~h}$ and 35 patients (3.9\%) underwent endoscopy after $48 \mathrm{~h}$. There were 35 patients who did not undergo endoscopy within $48 \mathrm{~h}$ of the first visit; most endoscopy procedures were performed after intensive care unit (ICU) hospitalization due to unstable vital signs. Among the total patients who underwent endoscopy, 735 received endoscopic hemostasis therapy; of these, patients underwent surgery $(n=11)$, trans-arterial embolization due to failure of the endoscopic treatment $(n=32)$, or both $(n=2)$. Among the patients who received endoscopic hemostasis, 128 had re-bleeding during the second endoscopy. Emergency endoscopic procedures were performed in most cases where patients had rebleeding during hospitalization and rebleeding after discharge. Thus, urgent endoscopic procedures within $12 \mathrm{~h}$ were performed in patients with rebleeding, and the mean average endoscopy timing in relation to rebleeding is $2.75 \mathrm{~h}$.

Calculation of pre-RS, GBS, AIMS65, PNED, and INBS was possible in all cases. Table 2 shows the patients' characteristics, chief complaint at first visit, treatment, and outcomes. The comorbidity scores were classified as ASA scores. The commonest endoscopic diagnosis was GU (67.8\%), and the second commonest was DU (19.3\%). There were 467 (51.6\%) patients admitted to the hospital within $8 \mathrm{~h}$. The average length of hospital stay 
1118 patients with suspected upper gastrointestinal bleeding from January 2013 to December 2017

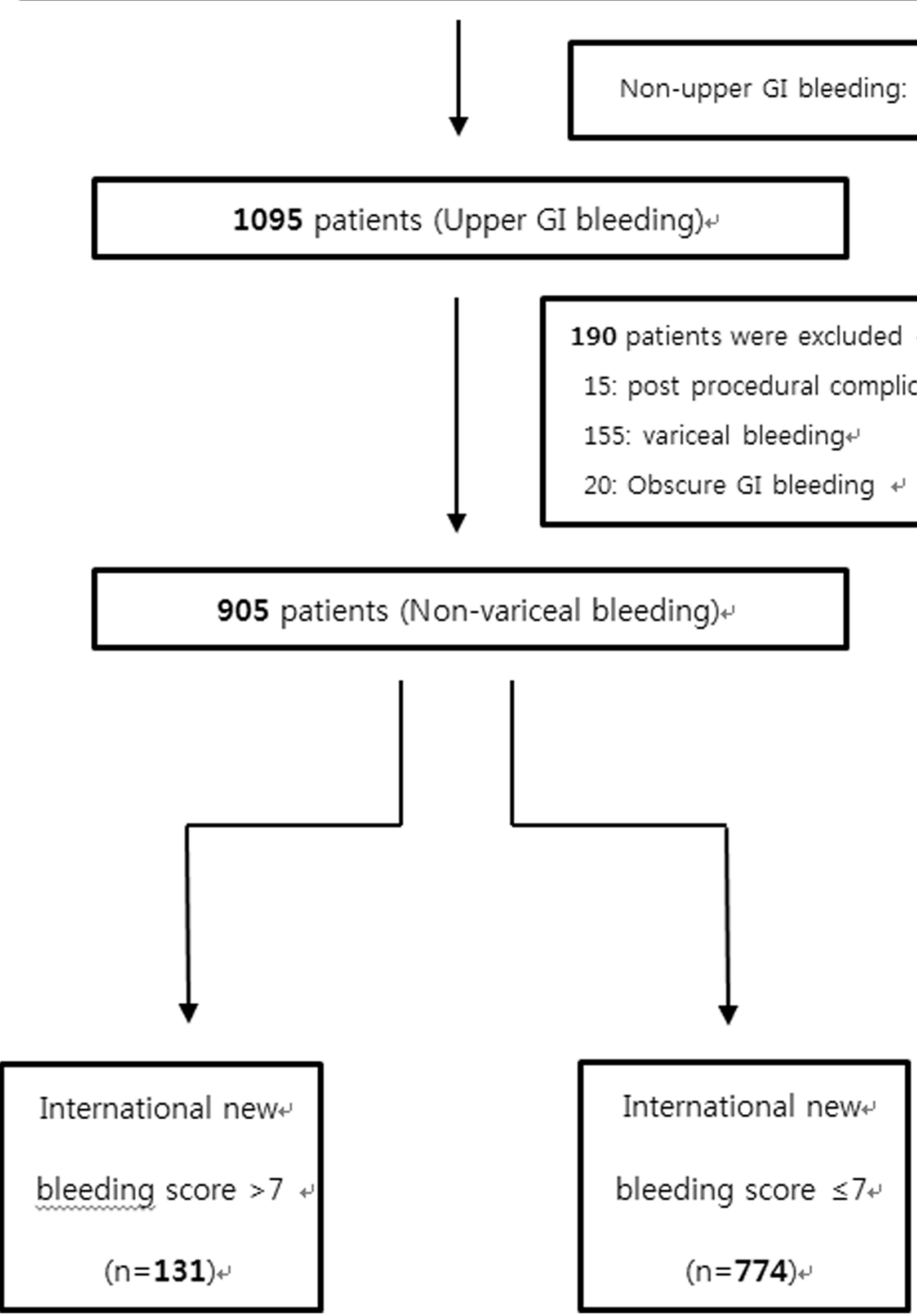

Fig. 1 Flow chart of patients enrolled in this study. Gl, gastrointestinal

for all patients was approximately 8.7 days. Among the 905 enrolled patients, only 31 patients (3.4\%) were hospitalized for $>30$ days A total of 44 patients (4.9\%) died within 30 days in hospital. A total of 44 patients died in the hospital within 30 days. Of these, 14 had a direct association with non-variceal upper gastrointestinal bleeding, 12 died of heart failure, 11 of septic shock, 4 of liver failure, 2 of cerebral infarction, and 1 of cerebral hemorrhage. The mean INBS scores in the mortality and survivor groups were $8.38 \pm 3.12$ and $3.86 \pm 2.56$ ( $P$ value $=0.027$, respectively.

\section{Comparison of bleeding scores' discriminative ability to} predict the 30-day mortality

In this study, INBS had the highest discriminative ability (area under the receiver operating characteristic (AUROC) curve 0.958 [95\% confidence interval (CI), 0.943-0.970]) in predicting mortality within 30 days compared with the AIMS65 (0.832; $P<0.001)$, PNED score $(0.865 ; P<0.001)$, Pre-RS $(0.802 ; P<0.001)$, and GBS $(0.765 ; P<0.001)$. The cut-off score was $>7$ with a sensitivity of $97.73 \%$ and a specificity of $89.79 \%$ (Table 3 and Fig. 2). Table 4 shows the discriminative ability of 
Table 2 Baseline characteristics, treatment, and clinical outcomes of the study population

\begin{tabular}{|c|c|}
\hline Patient related factor & All patients \\
\hline \multicolumn{2}{|l|}{ Characteristics } \\
\hline \multicolumn{2}{|l|}{ Sex } \\
\hline Male & $674(74.5 \%)$ \\
\hline Female & $231(25.5 \%)$ \\
\hline Age, years & $65.4 \pm 14.7$ \\
\hline$<65$ & $397(43.9 \%)$ \\
\hline$\geq 65$ & $508(56.1 \%)$ \\
\hline \multicolumn{2}{|l|}{ Alcohol } \\
\hline Never & $505(55.8 \%)$ \\
\hline Past & $29(3.1 \%)$ \\
\hline Present & $371(41.0 \%)$ \\
\hline \multicolumn{2}{|l|}{ Smoking } \\
\hline Never & $473(52.3 \%)$ \\
\hline Past & $219(24.2 \%)$ \\
\hline Present & $213(23.5 \%)$ \\
\hline ASA score 3 & $488(53.9 \%)$ \\
\hline ASA score 4 & $96(10.6 \%)$ \\
\hline \multicolumn{2}{|l|}{ Comorbidity } \\
\hline Diabetes mellitus & $251(27.7 \%)$ \\
\hline Hypertension & $453(50.1 \%)$ \\
\hline Angina & $81(9.0 \%)$ \\
\hline Cerebral infarction & $156(17.2 \%)$ \\
\hline ARDS & $28(3.1 \%)$ \\
\hline Disseminated malignancy & 87 (9.6\%) \\
\hline Liver cirrhosis & $67(7.4 \%)$ \\
\hline Sepsis & $29(3.2 \%)$ \\
\hline DIC & $26(2.9 \%)$ \\
\hline \multicolumn{2}{|l|}{ Chief complaint at first visit } \\
\hline Melena & $453(50.1 \%)$ \\
\hline Hematemesis & $282(31.2 \%)$ \\
\hline Syncope & $43(4.8 \%)$ \\
\hline Hematochezia & $66(7.3 \%)$ \\
\hline Anemia & $20(2.2 \%)$ \\
\hline Dizziness & $28(3.1 \%)$ \\
\hline Others & $13(1.4 \%)$ \\
\hline \multicolumn{2}{|c|}{ Endoscopic findings of acute NVUGIB } \\
\hline Gastric ulcer & $614(67.8 \%)$ \\
\hline Duodenal ulcer & $175(19.3 \%)$ \\
\hline Gastroduodenal ulcer & $11(1.21 \%)$ \\
\hline Esophageal ulcer & $7(0.77 \%)$ \\
\hline Mallory-Weiss syndrome & $47(5.19 \%)$ \\
\hline AGML & $4(0.44 \%)$ \\
\hline Angiodysplasia & $22(2.43 \%)$ \\
\hline
\end{tabular}

Table 2 Baseline characteristics, treatment, and clinical outcomes of the study population (Continued)

\begin{tabular}{ll}
\hline Patient related factor & All patients $(\boldsymbol{n}=905)$ \\
\hline Hemorrhagic gastritis & $12(1.32 \%)$ \\
Cancer-related bleeding & $13(1.76 \%)$ \\
Forrest classification (IA, IB, IIA) & $607(67.0 \%)$ \\
Forrest classification (IIB, IIC, III) & $298(32.9 \%)$ \\
Outcomes & \\
Admission before 8 h & $467(51.6 \%)$ \\
Admission day (mean) & 8.779 day \\
Endoscopy failure at first admission & $35(3.9 \%)$ \\
Endoscopic hemostasis therapy & $735(81.2 \%)$ \\
Endoscopic hemostasis failure & $52(7.0 \%)$ \\
Re-bleeding at 2nd endoscopy & $128(14.1 \%)$ \\
All-cause mortality in hospital in 30 days & $44(4.9 \%)$
\end{tabular}

Data are presented as mean $\pm \mathrm{SD}$, number (\%), or mean (range) NVUGIB Non-variceal upper gastrointestinal bleeding, ASA The American Society of Anesthesiology classification, ARDS Acute respiratory distress syndrome, DIC Disseminated intravascular coagulation, AGML Acute gastric mucosal Lesion

the evaluated scoring systems to predict length of hospital stay, rebleeding, and endoscopic hemostasis failure.

The cut-off value was used to organize the patients into the high- and low-to-moderate-risk groups. A total of 131 patients (14.5\%) were in the high-risk group; of these, 43 (32\%) died within 30 days. The low-tomoderate-risk group comprised 774 patients (85.5\%).

\section{Multivariate analysis for 30-day mortality}

On the basis of the risk factors mentioned in the scoring system for UGIB patients, we performed logistic regression to identify predictors associated with mortality in patients who visited our hospital. In the univariate regression analysis, the variables that were meaningful were male sex, old age, smoking, ASA score of 4, hypertension, acute respiratory distress syndrome (ARDS), disseminated malignancy, liver cirrhosis, sepsis, disseminated intravascular coagulation, systolic blood pressure, heart rate, hemoglobin, platelet count, blood urea nitrogen (BUN), creatinine, international normalized ratio, syncope at first visit, endoscopic failure at first admission in $48 \mathrm{~h}$, endoscopic hemostasis failure, and re-bleeding at the second endoscopy. Multivariate regression analysis was performed with the abovementioned variables that were significant in the univariate regression analysis (Table 5). Hypertension and systolic blood pressure could be duplicated, and only one was added. The multivariate analysis revealed that an ASA score of 4, ARDS, disseminated malignancy, creatinine, albumin, syncope at first visit, and endoscopic failure within $24 \mathrm{~h}$ during the first admission were associated with 30-day mortality. 
Table 3 Predictive and discriminative abilities for identification of patients at high-risk of mortality in 30 days

\begin{tabular}{lllllllll}
\hline System & Cut-off & $\begin{array}{l}\text { High-risk } \\
\mathrm{n}(\%)\end{array}$ & $\begin{array}{l}\text { Sensitivity } \\
(\%)\end{array}$ & $\begin{array}{l}\text { Specificity } \\
(\%)\end{array}$ & AUROC (95\% Cl) & $\begin{array}{l}\text { Mortality } \\
n(\%)\end{array}$ & $\begin{array}{l}\text { PPV } \\
(\%)\end{array}$ & $\begin{array}{l}\text { NPV } \\
(\%)\end{array}$ \\
\hline AIMS65 & $>1$ & $304(33.6)$ & 81.82 & 68.87 & $0.832(0.806$ to 0.856$)$ & $36(11)$ & 11.8 & 98.7 \\
PNED & $>4$ & $208(23)$ & 84.09 & 80.14 & $0.865(0.841$ to 0.886$)$ & $37(17)$ & 17.8 & 99 \\
Pre-RS & $>4$ & $165(18.2)$ & 59.09 & 83.86 & $0.802(0.774$ to 0.827$)$ & $26(15)$ & 15.8 & 97.6 \\
GBS & $>12$ & $219(24)$ & 63.64 & 77.82 & $0.765(0.736$ to 0.793$)$ & $28(12)$ & 12.8 & 97.7 \\
INBS & $>7$ & $131(14.5)$ & 97.73 & 89.79 & $0.958(0.943$ to 0.970$)$ & $43(32)$ & 32.8 & 99.9
\end{tabular}

INBS International bleeding risk score, Pre-RS Pre-endoscopic Rockall Score, GBS Glasgow Blatchford score, PNED Progetto Nazionale Emorragia Digestiva, AUROC Area under the receiver-operating characteristic curve, $\mathrm{Cl}$ Confidence interval

\section{Re-bleeding and length of hospital stay in the high-risk group}

An INBS cut-off value $>7$ was used to categorize patients into the high-score group (131 patients, 14.4\%) and low-score group (774 patients, 85.5\%). The highscore group had a relatively longer length of hospital stay and higher re-bleeding and endoscopic hemostasis failure rates than the low-score group (Table 6).

\section{Discussion}

In this study, we evaluated whether INBS is effective in predicting 30-day mortality in NVUGIB patients and its utility in predicting rebleeding or hospitalization duration. INBS was superior to other pre-endoscopy risk scoring systems in predicting 30-day mortality.

AUGIB is a common medical emergency associated with high morbidity and 30-day mortality rates $[1,16]$. More than $70 \%$ of AUGIB cases are NVUGIB, with GUs or DUs being the commonest. Mallory-Weiss syndrome, Dieulafoy's ulcer, angiodysplasia, and cancer-related bleeding are also causes of NVUGIB [17]. While therapies such as Helicobacter pylori eradication therapy and proton pump inhibitors might be expected to reduce peptic ulcers and decreased the mortality rate of NVUGIB patients, studies show that the mortality rate is still high at 6 to $14 \%$ due to population aging and the use of

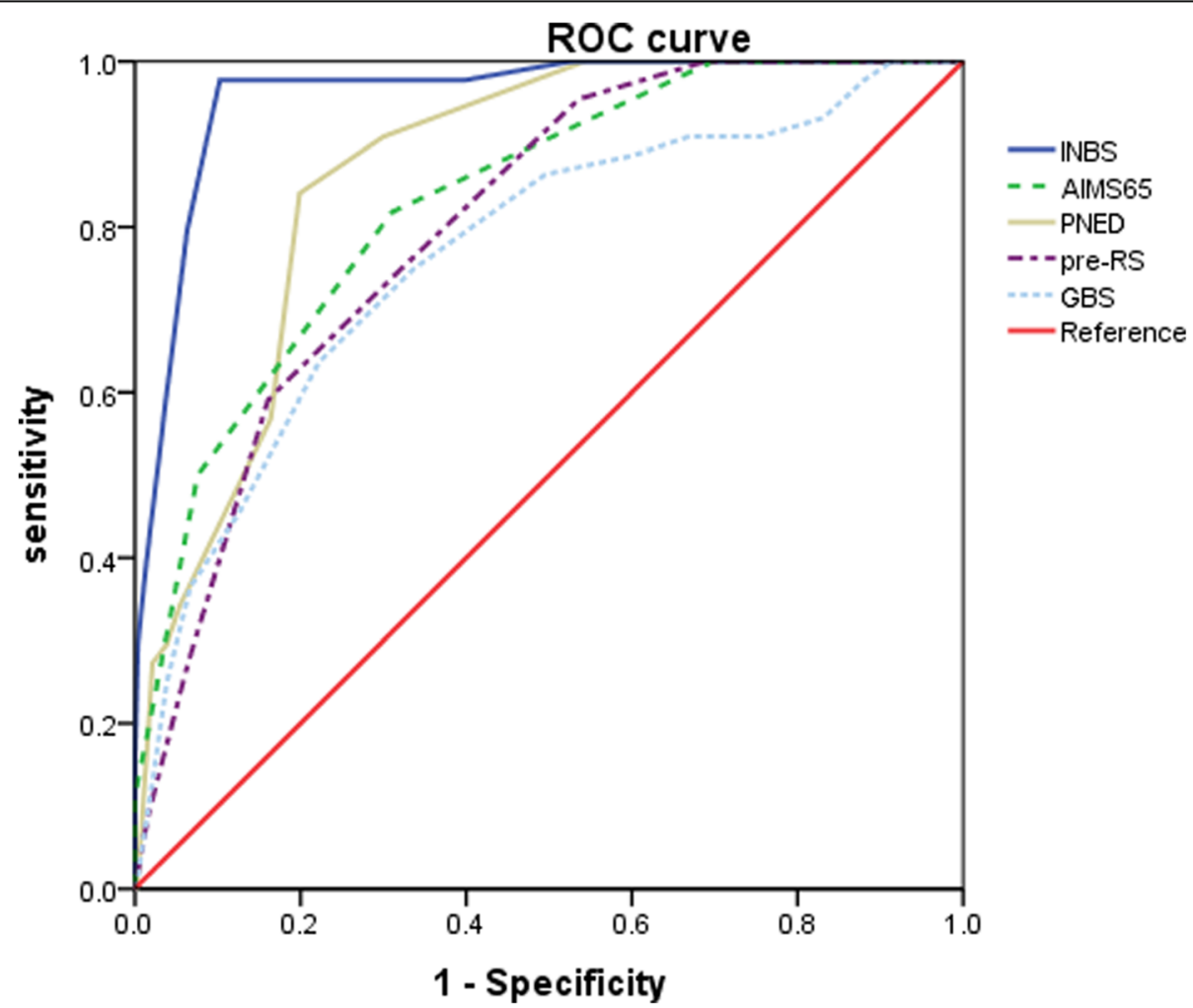

Fig. 2 Comparison of scoring systems in the prediction of 30-day mortality $(n=905)$. AUROC, area under receiver operating characteristic curve [95\% CI]; INBS, international new bleeding score; Pre-RS, pre-endoscopic Rockall score; GBS, Glasgow Blatchford score; PNED, Progetto Nazionale Emorragia Digestiva score 
Table 4 Discriminative ability of the evaluated scoring systems

\begin{tabular}{|c|c|}
\hline Outcome by scoring system & AUROC (95\% Cl) \\
\hline \multicolumn{2}{|l|}{ Length of hospital stay } \\
\hline AIMS65 & 0.691 (0.660 to 0.721$)$ \\
\hline PNED & 0.797 (0.769 to 0.823$)$ \\
\hline Pre-RS & 0.697 (0.666 to 0.727$)$ \\
\hline GBS & 0.641 (0.608 to 0.672$)$ \\
\hline INBS & 0.710 (0.679 to 0.739$)$ \\
\hline \multicolumn{2}{|l|}{ Re-bleeding rate } \\
\hline AIMS65 & 0.626 (0.593 to 0.657$)$ \\
\hline PNED & 0.854 (0.829 to 0.876$)$ \\
\hline Pre-RS & 0.643 (0.610 to 0.674$)$ \\
\hline GBS & 0.621 (0.589 to 0.653$)$ \\
\hline INBS & 0.636 (0.603 to 0.667$)$ \\
\hline \multicolumn{2}{|c|}{ Endoscopic hemostasis failure } \\
\hline AIMS65 & 0.676 (0.645 to 0.707$)$ \\
\hline PNED & 0.984 (0.973 to 0.991$)$ \\
\hline Pre-RS & 0.686 (0.654 to 0.716$)$ \\
\hline GBS & 0.688 (0.656 to 0.718$)$ \\
\hline INBS & 0.710 (0.679 to 0.739$)$ \\
\hline
\end{tabular}

anti-platelet drugs [18-21]. In these NVUGIB patients, timely hemostatic endoscopic procedures are important for survival improvement. For a successful treatment, assessing the hemodynamic status and appropriate risk measurement are necessary. Thus, classifying high-risk NVUGIB patients who have arrived at the ER using a highly efficient scoring system is important to help predict prognosis and direct appropriate treatment [7].

A variety of indicators (AIMS65 [10, 11], GBS [9], PreRS [8], PNED [12]) have been developed and evaluated to assess the risk of NVUGIB. Hyett et al. found that the AIMS65 score was superior to GBS in predicting death, but the GBS was better in predicting the need and the number of packed red blood cell transfusions [22]. In a cohort study of 424 participants, AIMS65 was also superior to GBS and Pre-RS in predicting hospital mortality, ICU admission, and loss of conscious [23]. In a European study, the usefulness of GBS, Pre-RS, and AIMS65 in patients with UGIB was assessed; however, there was no difference in mortality or re-bleeding frequency among the three scoring systems, and GBS was the best predictor of transfusion [24]. In another European study of 309 patients with UGIB, AIMS65, GBS, and Pre-RS were reported to be similar when predicting patient mortality; however, the need for endoscopic intervention was better predicted by AIMS65 and GBS [25, 26]. In a study on the utility of GBS and
AIMS65 conducted in the United States and involving 165 patients with NVUGIB aged $\geq 65$ years, GBS was superior to AIMS65 in predicting mortality [15]. The evaluation of the usefulness and predictability of the scoring system for assessing the prognosis of NVUGIB varies according to each study. The INBS ${ }^{13}$ scoring system that we have developed provides clear criteria for the 30-day mortality risk of patients with NVUGIB and has been shown to predict mortality better than the previous scoring systems. It is a predictive scoring system similar to the Pre-RS and PNED scores. However, INBS provides clear criteria for cirrhosis, differentiation of ASA scores according to hemodialysis, and blood tests to assess liver and renal functions. In contrast to previous scoring systems, the INBS included medical history including liver, renal and heart failure, in addition to the objective metabolic and biochemical indicators which we have described.

Our research suggests several strengths based on this new scoring system. First, this study validated INBS against the Pre-RS, GBS, AIMS65, and PNED risk stratification scores for predicting 30-day mortality. INBS was superior to other pre-endoscopy risk scores in predicting 30-day mortality. AIMS65, PNED, and Pre-RS showed higher mortality predictions with an AUROC $>0.8$, but it had lower values compared to INBS. Secondly, variables considered as risk factors in each scoring system were confirmed in this study. In the multivariate analysis, an ASA score of 4, ARDS, disseminated malignancy, creatinine, albumin, syncope at first visit, and failure of endoscopic treatment within $24 \mathrm{~h}$ of the first visit were identified as risk factors for death in NVUGIB patients. The risk of death due to underlying disease factors, aggravation of liver and kidney diseases, and failure of endoscopic treatment at the first visit were confirmed. The significant death risk factors in this study were similar to the death risk factors already reflected in INBS. INBS has proposed criteria to identify liver and renal failures through liver cirrhosis, decreased albumin levels, and increased BUN and creatinine levels. The severity of the underlying disease was scored using the ASA classification. Thirdly, we classified the patients into the highand low-to-moderate-risk groups based on the INBS cutoff value of $>7$. The cut-off value was the same to that published in a previous study of $\geq 8$ for the high-risk group [16]. In our study, we showed that the high INBS group had a relatively long hospital stay and high rebleeding and endoscopic hemostasis failure rates. The cause of death from bleeding was one of the predictable outcomes if the patient was unable to tolerate hemostatic treatment due to a poor general condition or bleeding from cancer and massive bleeding from the large vessels. Therefore classification of patients using INBS could be used as a tool to increase the probability 
Table 5 Univariate and multivariate analyses for 30-day mortality $(n=905)$

\begin{tabular}{|c|c|c|c|c|c|c|}
\hline \multirow[t]{2}{*}{ Risk factor } & \multicolumn{3}{|c|}{ Univariate analysis } & \multicolumn{3}{|c|}{ Multivariate analysis } \\
\hline & $\mathrm{OR}$ & $95 \% \mathrm{Cl}$ & Pvalue & OR & $95 \% \mathrm{Cl}$ & Pvalue \\
\hline \multicolumn{7}{|l|}{ Patient related factor } \\
\hline Sex (Male) & 2.106 & $1.132-3.918$ & 0.019 & 1.449 & $0.346-6.060$ & 0.611 \\
\hline Age & 1.031 & $1.007-1.056$ & 0.012 & 1.017 & $0.967-1.069$ & 0.507 \\
\hline \multicolumn{7}{|l|}{ Alcohol } \\
\hline Never & 1.000 & & & & & \\
\hline Present & 1.548 & $0.842-2.844$ & 0.159 & & & \\
\hline \multicolumn{7}{|l|}{ Smoking } \\
\hline Never & 1.000 & & & & & \\
\hline Present & 0.442 & $0.228-0.857$ & 0.016 & 0.383 & $0.106-1.385$ & 0.143 \\
\hline ASA score 3 & 1.383 & $0.742-2.579$ & 0.307 & & & \\
\hline ASA score 4 & 200.279 & $60.103-667.385$ & 0.000 & 111.642 & $16.31-764.083$ & 0.000 \\
\hline \multicolumn{7}{|l|}{ Comorbidity } \\
\hline Diabetes mellitus & 1.318 & $0.693-2.508$ & 0.4 & & & \\
\hline Hypertension & 2.481 & $1.281-4.806$ & 0.007 & & & \\
\hline Angina & 0.735 & $0.222-2.427$ & 0.613 & & & \\
\hline Cerebral infarction & 1.440 & $0.696-2.981$ & 0.325 & & & \\
\hline ARDS & 68.151 & $27.674-167.829$ & 0.000 & 19.530 & $2.795-136.471$ & 0.003 \\
\hline Disseminated malignancy & 3.930 & $1.943-7.949$ & 0.000 & 9.020 & $1.741-46.716$ & 0.009 \\
\hline Liver cirrhosis & 3.021 & $1.343-6.793$ & 0.008 & 1.050 & $0.171-6.51$ & 0.958 \\
\hline Sepsis & 22.147 & $9.804-50.029$ & 0.000 & 0.695 & $0.124-3.894$ & 0.679 \\
\hline DIC & 156.313 & $54.178-450.991$ & 0.000 & 3.430 & $0.583-20.158$ & 0.173 \\
\hline \multicolumn{7}{|l|}{ Vital sign } \\
\hline SBP & 0.968 & $0.954-0.982$ & 0.000 & 1.026 & $1.000-1.052$ & 0.052 \\
\hline $\mathrm{HR}$ & 1.016 & $1.002-1.030$ & 0.029 & 1.020 & $0.991-1.050$ & 0.178 \\
\hline \multicolumn{7}{|l|}{$L a b$} \\
\hline $\mathrm{Hb}$ & 0.803 & $0.706-0.914$ & 0.001 & 0.901 & $0.679-1.194$ & 0.468 \\
\hline PLT & 0.993 & 0.989-0.998 & 0.002 & 0.999 & 0.993-1.005 & 0.707 \\
\hline BUN & 2.356 & $1.277-4.346$ & 0.006 & 0.334 & $0.083-1.349$ & 0.124 \\
\hline $\mathrm{Cr}$ & 1.012 & $1.003-1.020$ & 0.006 & 1.434 & $1.031-1.996$ & 0.032 \\
\hline Alb & 0.099 & $0.053-0.186$ & 0.000 & 0.182 & $0.045-0.726$ & 0.016 \\
\hline INR & 1.539 & $1.230-1.927$ & 0.000 & 1.596 & $0.857-2.972$ & 0.141 \\
\hline \multicolumn{7}{|l|}{ Chief complaint at first visit } \\
\hline Syncope & 19.449 & $9.488-39.865$ & 0.000 & 5.985 & $1.294-27.687$ & 0.022 \\
\hline \multicolumn{7}{|l|}{ Admission and Endoscopy } \\
\hline Admission before $8 \mathrm{~h}$ & 0.794 & $0.432-1.462$ & 0.459 & & & \\
\hline Admissionday( $\geq 8$ days) & 6.503 & $3.345-12.645$ & 0.000 & 1.145 & $0.268-4.890$ & 0.855 \\
\hline \multicolumn{7}{|l|}{ Outcomes } \\
\hline Endoscopy failure at first admission & 27.903 & $13.072-59.561$ & 0.000 & 8.272 & $1.558-43.104$ & 0.012 \\
\hline Endoscopy hemostasis failure & 6.667 & $3.146-14.128$ & 0.000 & 1.109 & $0.235-5.226$ & 0.896 \\
\hline Re-bleeding at 2nd endoscopy & 2.720 & $1.383-5.352$ & 0.004 & 0.586 & $0.127-2.702$ & 0.493 \\
\hline
\end{tabular}

ASA The American Society of Anesthesiology classification, ARDS Acute respiratory distress syndrome, DIC Disseminated intravascular coagulation, SBP Systolic blood pressure, $\mathrm{HR}$ Heart rate, $\mathrm{Hb}$ Hemoglobin, PLT Platelet, BUN Blood urea nitrogen, $\mathrm{Cr}$ Creatinine, Alb Albumin, INR International normalized ration, $\mathrm{Cl}$ Confidence interval 
Table 6 Long-term hospital stay and occurrence of re-bleeding between high-risk group and low-to-moderate risk group in INBS

\begin{tabular}{llll}
\hline & High-risk group $(n=131)$ & Low-to-moderate risk group $(n=774)$ & $P$ value \\
\hline Admission day $(\geq 8$ days) & $86(65 \%)$ & $45(5 \%)$ & $<0.001$ \\
Re-bleeding & $36(27 \%)$ & $92(11 \%)$ & $<0.001$ \\
Endoscopic hemostasis failure & $23(17 \%)$ & $29(3.7 \%)$ & $<0.001$ \\
\hline
\end{tabular}

*Chi-square

of successful hemostasis and to shorten the hospitalization period through rapid endoscopic treatment and intensive monitoring.

In Korea, tertiary medical care institutions properly and actively perform endoscopy in patients. Therefore it would be helpful for the doctors who perform such procedures to have a classification standard score to help determine the appropriate timing of endoscopy and to predict the prognosis of NVUGIB patients. Using INBS, the identification of patients with a high risk of death is possible, allowing targeted management and interventions that may improve outcome.

This study has some limitations. First, the present investigation was a retrospective, single-center study, which can be a confounding factor. Therefore, a larger sample size and a prospectively designed study are needed to confirm the effectiveness of INBS. Second, this is an observational study, which focused on a high-risk mortality factor and classified high-risk patients. However, the criteria for low-risk patients with low scores were not established, and neither the criteria for the need for endoscopic treatment nor those for outpatient follow-up were presented. Given the nature of the tertiary medical institutions, most patients visiting the ER with AUGIB are often referred from other medical institutions because of the severity of the disease. Thus, doctors often think that endoscopy should be performed or patients want to undergo endoscopy. Therefore, examining our study subjects is important to confirm the suitability of the score in selecting low-risk patients to receive outpatient treatment without endoscopy. In addition, the INBS scoring system is limited in its use as a criterion for selecting low-risk groups, because it is weighted towards identifying patients who are at risk of sudden aggravation or death from liver or kidney disease. Although this study has several limitations, we think that it has laid the foundation for larger, multi-center, prospective studies of the utility of the INBS scoring system. Specifically, such studies would be designed to investigate whether carrying out early endoscopy, and second-look endoscopy on the basis of the degree of risk identified by this new scoring system can improve patient outcomes.

\section{Conclusion}

This is a preliminary report of a new bleeding score which may predict 30-day mortality better than the other scoring systems. High-risk patients could be screened using this new scoring system to predict 30day mortality, longer hospital admission, re-bleeding, and endoscopic hemostasis failure. The use of this scoring system seemed to improve the outcomes of nonvariceal UGIB patients in this study, through proper management and intervention.

\section{Abbreviations}

AUGIB: Acute upper gastrointestinal bleeding; NVUGIB: Non-variceal upper gastrointestinal bleeding; INBS: International new bleeding score; RS: The Rockall score; Pre-RS: Pre-endoscopic Rockall score; GBS: Glasgow-Blatchford score; PNED: Progetto Nazionale Emorragia Digestiva; ER: Emergency room; ASA: American Society of Anesthesiologists; AUROC: The area under the receiver operating characteristic; Cl: Confidence interval; GU: Gastric ulcer; DU: Duodenal ulcer; ARDS: Acute respiratory distress syndrome; BUN: Blood urea nitrogen

\section{Acknowledgements}

Not applicable.

\section{Authors' contributions}

HSM supervised the entire study and participated in the study design. MSK, JHP, JSK, SHK1, JKS, ESL, SHK2, BSL, and HYJ analyzed and interpreted the data. MSK and ISK performed statistical analyses. MSK and HSM wrote the manuscript. The authors read and approved the final manuscript.

\section{Funding}

This study received no financial support.

Availability of data and materials

The datasets used and analyzed in the current study are available from the corresponding author on reasonable request.

Ethics approval and consent to participate

This study was approved by the Institutional Review Board of Chungnam National University Hospital (IRB number; CNUH 2019-02-024), and the requirement for obtaining written consent was waived because of the retrospective design of the study. All procedures performed in studies involving human participants were in accordance with the ethical standards of the institutional and/or national research committee and with the 1964 Helsinki Declaration and its later amendments or comparable ethical standards

\section{Consent for publication}

Not applicable.

\section{Competing interests}

The authors have no conflicts of interest to declare.

\section{Author details}

${ }^{1}$ Division of Gastroenterology, Departmentof Internal Medicine, Chungnam National University Hospital, Chungnam National University School of 
Medicine, 282 Munhwa-ro, Jung-gu, Daejeon 35015, Republic of Korea. ${ }^{2}$ Clinical Trials Center, Chungnam National University Hospital, Daejeon 34952, South Korea.

Received: 31 August 2019 Accepted: 12 June 2020

Published online: 17 June 2020

\section{References}

1. Kurien M, Lobo AJ. Acute upper gastrointestinal bleeding. Clin Med (Lond). 2015;15:481-5

2. Abougergi MS, Travis AC, Saltzman JR. The in-hospital mortality rate for upper GI hemorrhage has decreased over 2 decades in the United States: a nationwide analysis. Gastrointest Endosc. 2015:81:882-8.e.1.

3. Leontiadis Gl, Molloy-Bland M, Moayyedi P, Howden CW. Effect of comorbidity on mortality in patients with peptic ulcer bleeding: systematic review and meta-analysis. Am J Gastroenterol. 2013;108:331-45.

4. Sey MSL, Mohammed SB, Brahmania M, Singh S, Kahan BC, Jairath V. Comparative outcomes in patients with ulcer- vs non-ulcer-related acute upper gastrointestinal bleeding in the United Kingdom: a nationwide cohort of 4474 patients. Aliment Pharmacol Ther. 2019:49:537-45.

5. Gralnek IM, Dumonceau JM, Kuipers EJ, Lanas A, Sanders DS, Kurien M, et al. Diagnosis and management of nonvariceal upper gastrointestinal hemorrhage: European Society of Gastrointestinal Endoscopy (ESGE) guideline. Endoscopy. 2015;47:a1-46.

6. Barkun AN, Bardou M, Kuipers EJ, Sung J, Hunt RH, Martel M, et al. International consensus recommendations on the management of patients with nonvariceal upper gastrointestinal bleeding. Ann Intern Med. 2010:152:101-13.

7. Rockall TA, Logan RF, Devlin HB, Northfield TC. Risk assessment after acute upper gastrointestinal haemorrhage. Gut. 1996:38:316-21.

8. Tham TC, James C, Kelly M. Predicting outcome of acute non-variceal upper gastrointestinal haemorrhage without endoscopy using the clinical Rockall score. Postgrad Med J. 2006;82:757-9.

9. Blatchford O, Murray WR, Blatchford M. A risk score to predict need for treatment for upper-gastrointestinal haemorrhage. Lancet. 2000;356:1318-21.

10. Saltzman JR, Tabak YP, Hyett BH, Sun X, Travis AC, Johannes RS. A simple risk score accurately predicts in-hospital mortality, length of stay, and cost in acute upper Gl bleeding. Gastrointest Endosc. 2011;74:1215-24.

11. Nakamura S, Matsumoto T, Sugimori H, Esaki M, Kitazono T, Hashizume M. Emergency endoscopy for acute gastrointestinal bleeding: prognostic value of endoscopic hemostasis and the AIMS65 score in Japanese patients. Dig Endosc. 2014;26:369-76.

12. Marmo R, Koch M, Cipolletta L, Capurso L, Grossi E, Cestari R, et al. Predicting mortality in non-variceal upper gastrointestinal bleeders: validation of the Italian PNED score and prospective comparison with the Rockall score. Am J Gastroenterol. 2010;105:1284-91.

13. Laursen SB, Laine L, Dalton H, Murray IA, Schultz M, Ngu JH, et al. The international bleeding risk score: a new risk score that can accurately predict mortality in patients with upper Gl-bleeding. Gastroenterology. 2017; 152:S149-50.

14. Dobson G, Chong M, Chow L, Flexman A, Kurrek M, Laflamme C, et al. Guidelines to the practice of anesthesia - revised edition 2017. Can J Anaesth. 2017:64:65-91.

15. Jung $\mathrm{SH}$, Oh JH, Lee HY, Jeong JW, Go SE, You CR, et al. Is the AIMS65 score useful in predicting outcomes in peptic ulcer bleeding? World J Gastroenterol. 2014;20:1846-51.

16. Robertson M, Majumdar A, Boyapati R, Chung W, Worland T, Terbah R, et al. Risk stratification in acute upper Gl bleeding: comparison of the AIMS65 score with the Glasgow-Blatchford and Rockall scoring systems. Gastrointest Endosc. 2016;83:1151-60.

17. Holster IL, Kuipers EJ. Management of acute nonvariceal upper gastrointestinal bleeding: current policies and future perspectives. World J Gastroenterol. 2012;18:1202-7.

18. Alexandrino G, Domingues TD, Carvalho R, Costa MN, Lourenço LC, Reis J. Trends of endoscopy timing in patients with acute upper gastrointestinal bleeding. Clin Endosc. 2019;52:47-52.

19. Nagasue T, Nakamura S, Kochi S, Kurahara K, Yaita H, Kawasaki K, et al. Time trends of the impact of Helicobacter pylori infection and non-steroidal antiinflammatory drugs on peptic ulcer bleeding in Japanese patients. Digestion. 2015;91:37-41.
20. Wuerth BA, Rockey DC. Changing epidemiology of upper gastrointestinal hemorrhage in the last decade: a nationwide analysis. Dig Dis Sci. 2018:63:1286-93.

21. Li L, Geraghty OC, Mehta Z, Rothwell PM, Oxford Vascular Study. Agespecific risks, severity, time course, and outcome of bleeding on long-term antiplatelet treatment after vascular events: a population-based cohort study. Lancet. 2017;390:490-9.

22. Hyett BH, Abougergi MS, Charpentier JP, Kumar NL, Brozovic S, Claggett BL, et al. The AIMS65 score compared with the Glasgow-Blatchford score in predicting outcomes in upper Gl bleeding. Gastrointest Endosc. 2013;77:551-7.

23. Robertson M, Majumdar A, Boyapati R, Chung W, Worland T, Terban R, et al. Risk stratification in acute upper Gl bleeding: comparison of the AIMS65 score with the Glasgow-Blatchford and rock-all scoring systems. Gastrointest Endosc. 2016:83:1151-60.

24. Budimir I, Gradiser M, Nikolic M, Barsic N, Ljubicic N, Kralj D, et al. Glasgow Blatchford, pre-endoscopic Rockall and AIMS65 scores show no difference in predicting rebleeding rate and mortality in variceal bleeding. Scand J Gastroentrerol. 2016;51:1375-9.

25. Martinez-Cara JG, Jimenez-Rosales R, Ubeda-Munoz M, de Hierro MJ, de Teresa J, Redondo-Cerezo E. Comparison of AIMS65, Glasgow-Blatchford score, and Rockall score in a European series of patients with upper gastrointestinal bleeding: performance when predicting in-hospital and delayed mortality. United European Gastroenterol J. 2016;4:371-9.

26. Tang Y, Shen J, Zhang F, Zhou X, Tang Z, You T. Scoring systems used to predict mortality in patients with acute upper gastrointestinal bleeding in the ED. Am J Emerg Med. 2018;36:27-32.

\section{Publisher's Note}

Springer Nature remains neutral with regard to jurisdictional claims in published maps and institutional affiliations.
Ready to submit your research? Choose BMC and benefit from:

- fast, convenient online submission

- thorough peer review by experienced researchers in your field

- rapid publication on acceptance

- support for research data, including large and complex data types

- gold Open Access which fosters wider collaboration and increased citations

- maximum visibility for your research: over $100 \mathrm{M}$ website views per year

At $\mathrm{BMC}$, research is always in progress.

Learn more biomedcentral.com/submissions 